\title{
INVESTIGATIONS OF ROOT DISEASE OF SUGAR CANE.
}

\author{
By J. Matz.
}

The root-disease problem of sugar cane has engaged the attention of many workers in the past, including the work of A. Howard on "Some Diseases of the Sugar Cane in the West Indies," published in 1903 in the Annals of Botany V. 17, pp. 373-412, in which the author gives an account of his experiments to establish a relation between Marasmius sacchari Wakker, and the root disease of cane in Barbados. From those experiments it appears that Marasmius is capable of causing damage to the sugar cane during certain unfavorable seasons. Under favorable conditions for the growth of the sugar cane plant the presence of the fungus on the plant did not seem to have a deleterious effect. The question arises if unfavorable seasons and unfavorable conditions in the field alone are not sufficient to produce an effect that might be similar to that which may result from a fungus attack on the roots of the plant. The fungus Marasmius sacchari is very common in a large part of the cane fields of Porto Rico and it has generally been taken to be the cause of root disease here. Johnston and Stevenson while describing root disease of cane in the Journal of the Department of Agriculture of Porto Rico, Vol. 1, No. 4, 1917, express doubt as to "the exact status of root disease with respect to the parasitism of Marasmius, Himantia, Odontia, or possibly other forms, * * * while it is generally held that Marasmius at least is a true parasite really definitive evidence is lacking." During the past year an attempt was made to determine, if possible, the exact nature of root disease of cane, and, the facts thus far learned are of sufficient interest to warrant their publication.

\section{WHAT IS ROOT DISEASE OF CANE?}

By root disease of any plant it is usually understood to mean decay of roots which result in either the rotting of the basal part of the plant or in a mere stunting and subsequent withering of the whole plant. In either case the symptoms should be clear enough as not to confuse it with other diseases. In cane there are many plants which could easily be taken as affected with root disease that may not be suffering from root disease at all. Borers of various 
kinds, drouth, lack of eultivation, gum disease, top rot, and lack of drainage produce effects that may be taken for root disease. The cane plant as a whole has such a structure that injuries to the lower portion whether caused by mechanical agents such as boring insects or by the physical conditions of soil, or whether by fungi and bacteria which either clog up the conducting channels or fibers thus starving the plant or simply decompose the roots through parasitism, the effects on the plant as a whole in all cases would be drying of leaves from the tips, top rot, stunting and shortening of the joints and a multiplicity of short sprouts. Therefore to distinguish root disease proper from other troubles of the cane which arise in the root region the term root disease is restricted here to mean a decomposition of roots taking place on account of the invasion of fungi. The symptoms of root disease therefore are primarily a decomposition or lack of healthy roots, dry leaves and stunted appearance of the cane. Top rot may also result indirectly on account of lack of sufficient roots to take up and conduct necessary water and food to the plant. The binding of the lower leaf sheaths has been generally taken for a symptom of root disease; that is, when Marasmius sacchari was taken as the parasitic cause of the disease. That symptom is not necessarily an accompaniment when another fungus is concerned with the decay of roots. Cane ratoons which exhibit all the effects of root disease, being stunted and having the lower portions of the stalks covered with adhering dry leaf sheaths and yet binding was not observed and the yellowish white mycelium of $M a$ rasmius was not noticed in between them. It is, however, reasonable to assume that the same ratoons had they grown in low and moist locations and if Marasmius had been present in that soil that binding would have taken place, as the fungus thrives well on dead cane leaves and stalks. It is quite possible that under unfavorable conditions of growth the cane plant may fall a prey to an organism which is not parasitic enough to be able to attack the cane had it grown under conditions condusive to strength and vigor. Such cases no doubt exist. But the semi-parasitic organisms do not add much more damage to the amount which is already caused by the unfavorable conditions, which may be poor drainage, lack of water and no cultivation or undesirable varieties planted on unsuitable soil lacking in plant food elements. The important factor in true root disease should be an organism which is capable of attacking essential roots and destroying them. With this point in view a search was made 
to find and isolate microorganisms from the interior of young but partially affected roots of cane. This effort was rewarded by finding Rhizoctonia, a root-destroying organism in the tissues of young roots, on seven different occasions, and Pythium sp. on two occasions. At the same time Rhizoctonia species were isolated from a large variety of plants other than cane, proving that this form genus is widely distributed in soils of Porto Rico.

\section{THE ISOLATIONS OF FUNGI FROM CANE ROOTS.}

The first isolation trial was made in December, 1918, immediately after the writer had become connected with the Insular Experiment

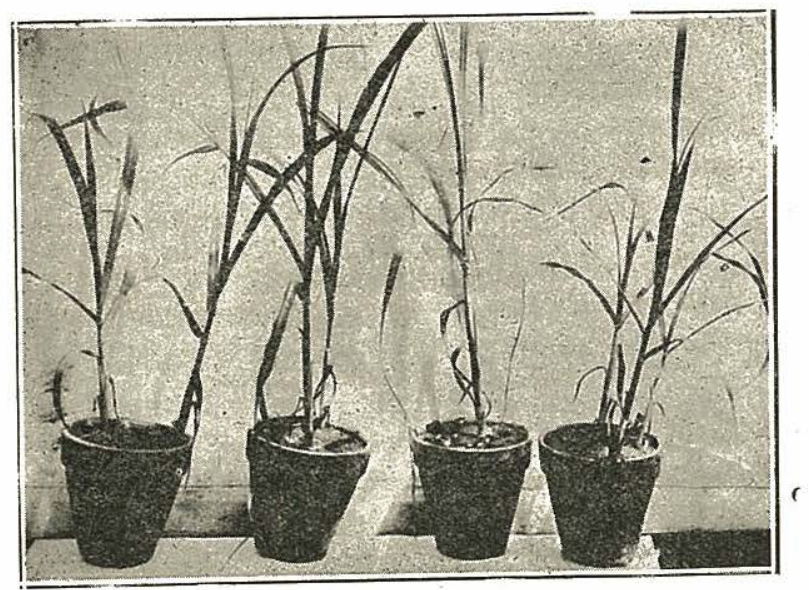

FIG. 1. The two cane plants in the middle were inoculated, at the time of planting the seed, with Marasmius, the plant on the right with Rhizoctonia solani (?) and the one on the left is a check.

Station, from cane at the Santa Rita estate near Yauco. The cane plants were only a few months old from a gran cultura planting. The leaves did not show any abnormal appearances at that stage, except yellow-stripe disease in some plants. On pulling up some plants, both yellow-striped and healthy, it was observed that the roots of some, though numerous, were mostly brown and partly decayed. Although the brown coloration is natural with older roots, the young and fleshy rootlets, however, were stained an unnatural red and the root cortex was dissolved and decomposed in part. Two plants were brought to the laboratory, and the younger and red-brown root- 
lets were cut off, washed in running water, and with a flamed scalpel bits of the reddish and soft tissue were planted in corn meal agar plates. In about two days three fungi were observed in the plates. One was Rhizoctonia with its characteristic even mycelium and anastomosing side branches, another was a Pythium, laterly determined as such by its fructifications, and several colonies of Trichoderma. These three fungi were transfered to several tubes containing sterilized green bean pods. The Rhizoctonia transfers began to form yellowish sclerotia in about four days. At first these sclerotia were composed of loose but short and stout hyaline hyphæ, later the masses became more compact and took on a deeper color. In about 3 weeks the mycelium in the tube became buff brown, and the sclerotia became darker and have attained a size of 1 to 3 millimeters. They are rounded and covered with a lighter growth of short hyphæ. The culture presents all the general characters of the well-known Rhizoctonia solani, of which the writer has a culture which was isolated in Florida and compared with a culture of the same from Dr. B. M. Duggar of the Missouri Botanical Garden. Whether this cane Rhizoctonia is identical with or is a different strain from $R$. solani is reserved for another paper to be published in the future.

\section{INOCULATION EXPERIMENT.}

Before searching any further for more fungi on cane roots an inoculation experiment was made to test the relation of the abovenamed three fungi to cane root decay. Rayada cane seed, each consisting of at least one entire internode and two nodes, were cut with a sharp knife about one-half inch above and below their respective nodes. These pieces were washed for 15 minutes in a $1: 1000$ solution bichloride of mercury, rinsed in running water and planted in steamsterilized soil in six-inch pots. Three seed pieces were inoculated with the above Rhizoctonia, three with Pythium and three with Trichoderma. This was done by placing a bean pod culture of one of the organisms on the seed piece and covering it all with about one inch of soil. The pots were watered and kept covered with paper for three days from inoculation. On the fourth day the top layers of soil were removed and the young roots, some of which had attained one inch in length, were examined. It was found that where Rhizoctonia and Pythium were used some of the young roots were red and soft. Small pieces of the latter were examined with the aid of the microscope and it could plainly be seen that the two fungi had entered 
and grown into the interior of the roots, causing a decomposition of the cells of the fleshy parts of the root. The characteristic Rhizoctonia mycelium, with its almost perpendicular branching and dis-

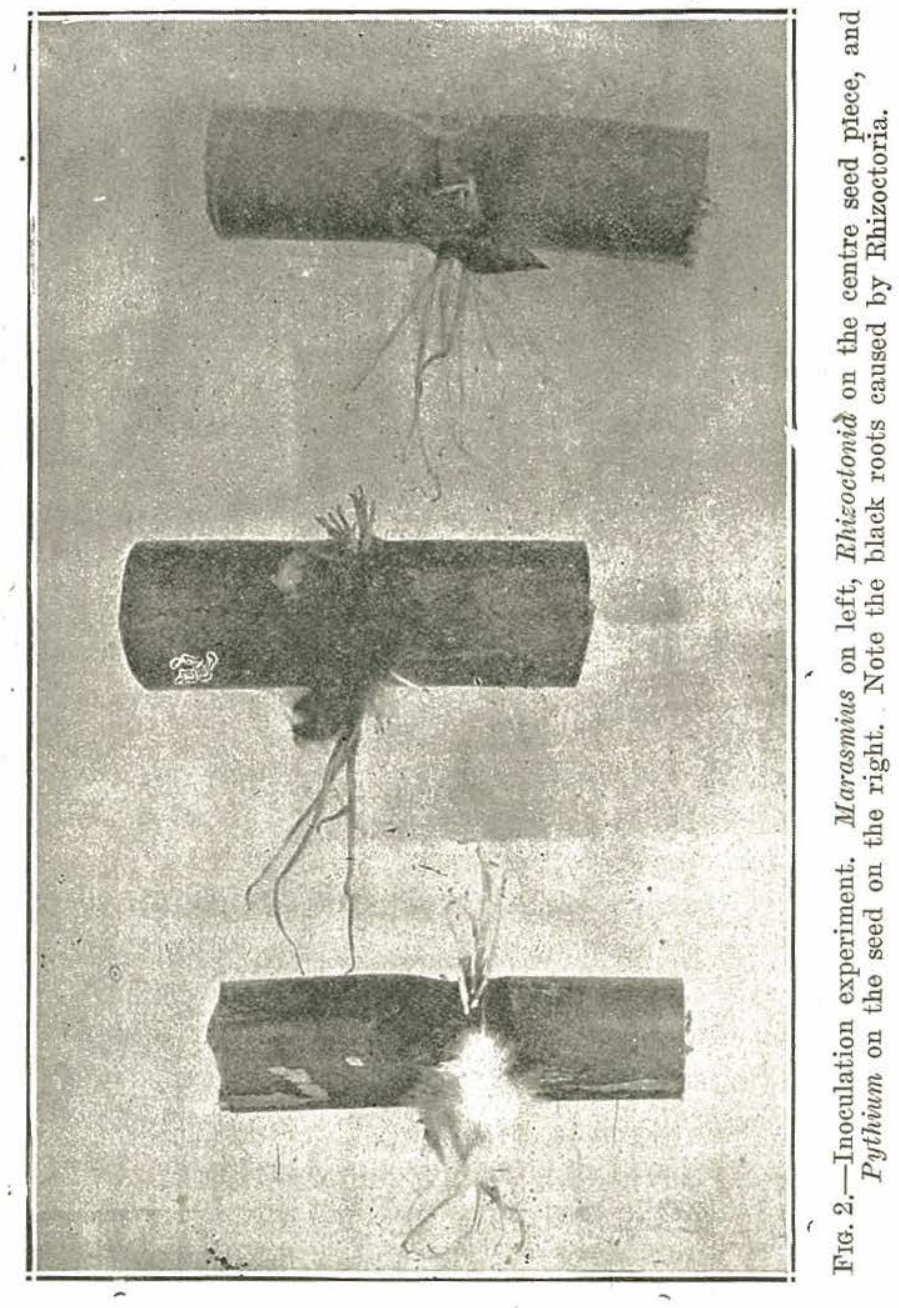

tinct walls could be seen to ramify in and between the cells of the roots in the parts where that fungus was used as the inoculum, and the stout, uneven and hyaline, non septate mycelium of Pythium was observed to have grown around and betwcen many root cells in 
the pots where this fungus was used. The fungus Trichoderma did not produce any visible change in the roots of the cane.

Having that much success with this first trial another experiment was made, using the three above-named fungi and in addition pure cultures of Marasmius sacchari, and Odontia saccharicola. Again Rhizoctonia and Pythium gave positive results while Trichoderma, Marasmius and Odontia did not affect the young roots. In this experiment six seeds were inoculated with Rhizoctonia, six with Pythium, three with Marasmius, three with Odonia, three with Trichoderma and three were left as checks. Two strains of Marasmius were used, one was from a culture growing in pure state on sterilized cane leaves in flasks, the other was isolated by the writer from spores of hymeniums collected in a cane field at Río Piedras. The two strains were similar in all appearances, the first one probably having come from mycelium commonly found on leaf sheaths and basal parts of cane stalks. The method employed to obtain spore cultures from Marasmius and Odontia was by making a spore print on sterilized corn-meal agar. A drop of agar was placed on the inside of a Petri dish cover and a portion of the hymenium was stuck onto the agar. Then the top was placed over a corn-meal agar poured plate permitting the spores to drop on the surface of the agar in the bottom dish. With fresh hymeniums a spore print on sterilized agar was thus obtained in 24 hours. Single spores could then be transferred from the edge of the print where they are not too thickly sown. Both fungi were grown on sterilized green bean pods. The growth of Marasmius in pure cultures, from single spores, was producing white strands similar in appearance to the fungus usually found in connection with binding of the lower leaf sheaths. Other cultures from the white mycelium, usually taken to be Marasmius, were also made and there was such an agreement of characters between these and the cultures from spores that the writer is inclined to the general belief that the common leaf-binding fungus in Porto Rico is no other than Marasmius sacchari. Further proof of the identity of the two forms was had by the fact that a culture of mycelium from matted leaf sheaths developed the sporebearing stage of Marasmius sacchari when placed in soil in pots in which cane was growing. The cultures of Odontia spores were rather slow growing, producing a short, grayish and thin growth of mycelium on bean pods, after a while becoming water soaked and giving to the bean pod itself an oily or more or less transparent aspect. There were no formations of mycelial strands or threads in these 
cultures. And the writer cou.d not find any similarity of character between these pure cultures and the thread mycelia commonly encountered on cane soils in the field.

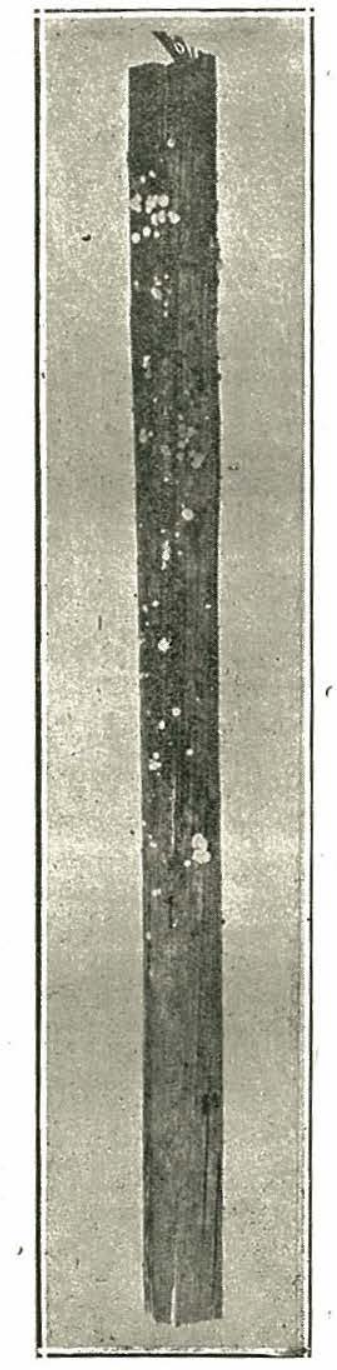

FIG. 3.-Sclerotial fungus on dea $d$ leaf of cane.

When the plants inoculated with Rhizoctonia, Pythium, Trichoderma, Marasmius, and Odontia, in the experiment mentioned above, were examined it. was noticed that in the Marasmius pots, although the white threads of the fungus had penetrated through the upper 
three or four inches of soil, the growing roots of the cane seed were not affected in any unusual way. Mycelium was observed on some rocts but no rotting took place. However, after three months from inoculation there could not be seen any appreciable difference in the growth between any of the inoculated plants and those. used as checks. A liberal amount of water has regularly been applied to the plants. When the water was cut off for two or three days, the ones inoculated with Rhizoctonia showed less vigor. Four months from inoculation the pots inoculated with Marasmius produced the fruiting stage of the fungus at the same time the cane plants were among the tallest and most vigorous ones. Fig. 1 is a photograph of four plants in this experiment. The two middle ones have been inoculated with Marasmius and are showing the fruiting caps of the fungus growing in the soil and at the bases of the young cane stalks. The plant on the left is a check, and on he right is one in which Rhizoceonic was used as the inoculum.

All the plants in the last experiment were later taken out of the pots and their root systems examined. It was apparent that the roots from the plants infected with Rhizoctonia were fewer in number and that many of the longer roots were brittle and decayed; the the same was noticed where Pythium was applied to the soil; in the case of Marasmius, although the fungus mycelium was plainly visible in amongst the soil particles, yet the roots did not show as much decay as in the first two; the same was true with the Odontia and Trichodermo infected plants. The roots of the check plants were normal. The plants were then set out in the field. All of them made a uniform growth with the exception of a larger number of dead lower leaves being present on those which were previously infected with Rhizoctonia.

At maturity the cane, all of which made a very good stand, was cut and allowed to ratoon. In the ratoons an unevenness of growth in the centre of the plot was observed. This unevenness was no doubt due to soil conditions, as the effect of the previous inoculations were entirely lost during the first season of growth after the transplanting to a new location. In this small plot of cane there became evident a stunting of the cane in a central area, a phenomenon which is not unusual in cane fields. In this particular case, the uneven stand in the cane was evidently due to a very compact soil, which became more so in the center of the plot during a season of heavy rainfall. 
In order to make close observation of the relation of the abovementioned fungi to root decay of cane a series of moist chamber inoculations were made as follows: Seed pieces of cane containing one or two buds were sterilized in a solution of 1:1000 bichloride of mercury and placed in sterilized and moist glass jars. Cultures of Rhizoctonia, Marasmius and Pythium were placed on the cane seed and the jars were covered with glass. Fig. 2 is a photograph of three seeds in this experiment. Rhizoctonia has in two weeks invaded

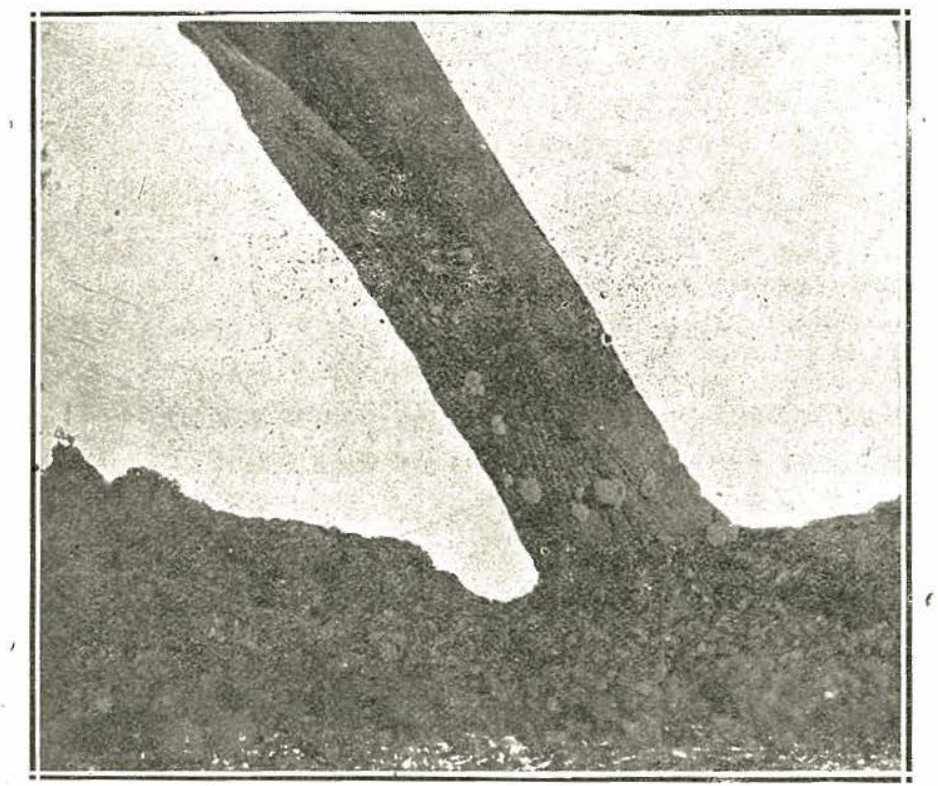

FIG. 4.-Sclerotia at the base of an inoculated cane plant.

the growing rootlets, the threads of the fungus growing on the whole length of the rootlets. Instead of being white or yellow the rootlets turned reddish brown and the smaller roots, or those which have arisen after the fungus has had time to develop its growth, did not attain any considerable length and they were abnormally brown instead of purple at the tips. Compact masses of the mycelium were plainly visible in the softened tissues of the attacked rootlets. Reisolations gave the same type of Rhizoctonia from these roots. Marasmius grew right alongside of the roots of seed on which it was 
placed, but there were no striking differences of any abnormal nature in appearance of these roots and the roots of seed in the check jars. Although the fungus mycelium of Marasmius was in contact with the roots there was no sign of decay in them. Pythium did not have the same injurious effect upon the roots as Rhizoctonia in this experiment. However, a few roots were observed to have been attacked and upon reisolation the same fungus was recovered. Experiments such as described above have been repeated several times, using different varieties of cane, and employing other strains of Rhizoctonia. The results have not always been uniform mainly due to the fact that other fungi and ferments would enter and cause decay of the seed pieces thus preventing normal development of roots. On several other occasions the inoculum would not grow in the jars as described, due, perhaps, to an early chemical change in the seed itself.

That the condition of the seed piece in itself plays an important part in the health of the first series of roots that arise at the time of germination has been observed on several occasions. For example, in one experiment mature Otaheite seed were used in the jars, the seed being placed on one end in the bottom of the jars in about onefourth inch of tap water. Not a single seed out of 24 germinated and the roots did not make much headway before they became arrested in growth and finally decayed. On the other hand, the same treatment when accorded to Rayada and Caledonia did not produce in them any growth-inhibitory symptoms. The seed pieces of the latter two kept sound and their roots in most of the jars attained normal lengths and were abundantly side branched. However, the seed of these two varieties if infected with the yellow-stripe disease produced many short-lived, red, roots when placed in moist jars as above. Of course, the cane bud produces its own roots after a while, but during the early stages of its growth it is dependent upon the mother seed piece and its root system in order to make good growth. If the seed piece is liable to become fermented sooner, either because of its natural lack of hardiness or because it was allowed to become weak on account of too prolonged exposure between the time it was cut and the time it was set in the ground, it is quite certain that it will give weak shoots which will be short lived mainly because such seed do not produce enough and vigorous roots.

Another form of Rhizoctonia was found in its sclerotial stage on 
the lower dead leaf sheaths of eane. (Fig. 3.) Kruger $^{1}$ in deseribing diseases of cane mentions three diseases which are associated with three distinct sterile fungi but which produce sclerotia. One of these, causing the red rot of leaf sheaths ond stalks, is Sclerotium Rolfsii, as can be plainly seen from Kruger's colored plate XIV. Another sclerotia-producing fungus he associates with the soir rot of the leaf sheaths. This fungus, he states, produces sclerotia of light orange-yellow color, are larger and softer than the former (Sclerotium Rolfsii). The fungus with the orange-yellow colored sclerotia is unknown to
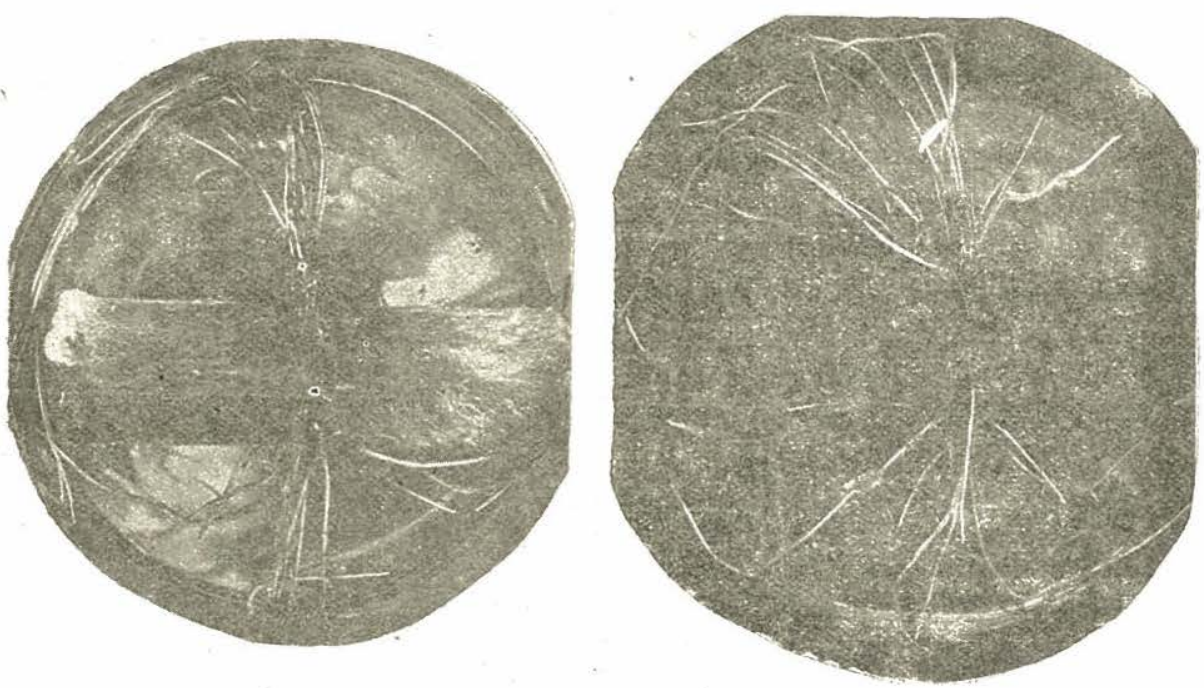

FIG. 5.-Seed on the left inoculated with pure culture of selerotial fungus, showing many black or diseased roots, seed on the right not inoculated, all roots being white.

the writer. On pages $443-447^{1}$ Kruger describes and illustrates a disease under the name of sclerotia disease of sugar-cane leaves. The fungus associated with the disease is most likely identical with the Rhizoctonia under discussion. The thin mycelium of this fungus is hardly noticed, but its gray to dark-gray and sometimes graybrown scletoria which are more or less rounded, concave and sometimes ridged are commonly found in damp and shaded locations on dead leaves near and sometimes on the ground. The fungus was grown in pure culture from, bits of sclerotia in corn-meal agar and

${ }^{1}$ W. Kruger, Das Zuekerrohr und seine Kultur.' 1899, pp. 433-466. 
on green bean pods. When a pure culture of the fungus was placed in sterilized soil in pots the mycelium grew rapidly in the soil and sclerotia were formed in large numbers on the moist surfaces of the soil and the walls of the pots. Pure cultures of the fungus were placed on seed cane in sterilized soil and the growth of the fungus on the young shoots and roots was observed (Fig. 4, 5, 6.) The shoots became reddish-brown and dry at their bases and began to dry at the tips as well. The fungus mycelium and sclerotia were adhering to the lower parts of the young cane shoots. Other seed planted at the same time and under similar conditions, but the soil in which these grew was not inoculated with the fungus, produced vigorous shoots. In order to prove whether this fungus is capable of attacking green leaves and their sheaths above ground, portions of growth of the fungus produced in culture tubes were placed on green leaves and sheaths of cane and covered with glass chimneys. The growth of the fungus on these was rather slow, it produced lesions of various sizes, the largest being one-half inch in length on one leaf. In all cases it produced one or more sclerotia which were identical with those from which the cultures were made.

Pure cultures of the same fungus were placed on young roots of cane seed placed in sterilized moist chambers. The fungus mycelium grew over the roots and it was noticed that many of the roots soon became partially brown. Upon examination it, was found that the fungus has penetrated into the soft tissue of the roots, and portions of these when planted in agar gave the identical fungus upon reisolation.

\section{CHARACTER OF THE FUNGUS.}

The fungus agrees with the general characters of the form-genus Rhizoctonia. Stevenson in the Annual Report of the Insular Experiment Station, of 1917, page 138, describes the fungus as Sclerotium griseum. This fungus is, according to the description and herbarium specimens deposited by him at this laboratory identical with the above Rhizoctonia. The sclerotia do not possess a distinct cortex, are not smooth and are homegenous in color throughout. When this fungus is grown in eulture tubes on sterilized bean pods it presents a very similar appearance to the growth of Rhizoctonia solani with the exception that the latter is darker brown. Other forms of Rhizoctonia similar to the Solani type have been grown by the writer in 
pure culture and which were very light in color. The selerotia of the above cane fungus are very irregular, flat and more or less loose in texture when produced in eulture tubes on bean pods. Since this fungus agrees more with the form genus Rhizoctonia than with Sclerotium the name Rhizoctonia grisea (n. comb.) is proposed.

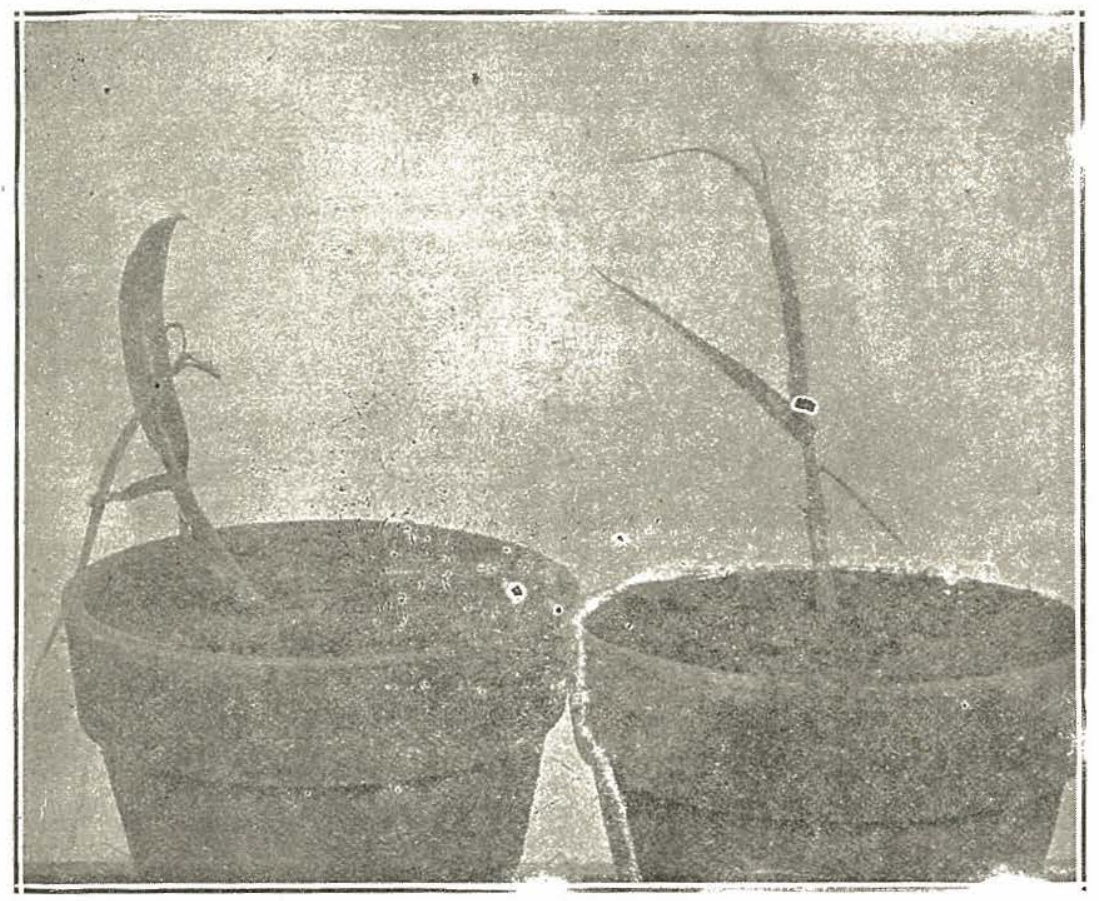

Fig. 6.-Effeets of sclerotial fungus on young shoots of eane.

\section{SUMMARY.}

Sugar cane roots, like many other plants, are attacked by the well-known fungi belonging to the genera Rhizoctonia and Pythium.

These fungi are common in the soils of Porto Rico.

More than one form of Rhizoctnia has been isolated from diseased roots of cane. 